\title{
Plasma Functionalization of Multi-Walled Carbon Nanotubes for Ammonia Gas Sensors ${ }^{\dagger}$
}

\author{
Alexander G. Bannov 1,* and Anton Manakhov 2,3 \\ 1 Novosibirsk State Technical University, 20 K. Marx, Novosibirsk 630073, Russia \\ 2 Research Institute of Clinical and Experimental Lymphology-Branch of the ICG SB RAS, 2 Timakova str., \\ Novosibirsk 630060, Russia \\ 3 RG Plasma Technologies, Central European Institute of Technology-CEITEC, Masaryk University, \\ Kamenice 5, Brno 625 00, Czech Republic \\ * Correspondence: bannov@corp.nstu.ru \\ + Presented at the 7th Electronic Conference on Sensors and Applications, 15-30 November 2020; Available \\ online: https://ecsa-7.sciforum.net/.
}

Published: 15 November 2020

\begin{abstract}
The role of plasma functionalization of multi-walled carbon nanotubes (MWCNTs) for room temperature ammonia gas sensors was investigated. Plasma functionalization of MWCNTs with maleic anhydride was carried out with various durations. Active material of gas sensor was investigated by scanning electron microscopy, Raman spectroscopy, and X-ray photoelectron spectroscopy. It has been shown that formation of functional groups on the surface of carbon nanotubes led to the increase in ammonia sensor response by 2-4 times. The increase of functionalization duration induces the rise of O:C from 0.28 to 0.335 , increase of sensor resistance, and the distortion of shape of I-V curves.
\end{abstract}

Keywords: carbon nanotubes; functionalization; plasma; gas sensor; ammonia; response; plasma treatment; functional groups

\section{Introduction}

Carbon nanotubes (CNTs) are of interest within last decades and the research on their synthesis, modification, and applications are still carried out all over the world. Multi-walled carbon nanotubes (MWCNTs) is a promising material for various applications due to their lower cost, simplicity of synthesis and scale-up compared to single-walled carbon nanotubes. MWCNTs can be used in polymer composites [1,2], hydrogen evolution reactions [3,4], electronics [5], biosensors [6], etc.

In addition, CNTs can be used as active material for gas sensors [7-9]. Recently, the research on room temperature gas sensors based on CNTs for ammonia detection is of particular interest [10-12]. However, the response of gas sensors based on untreated CNTs is low enough. Therefore, there are several approaches to enhance the sensing properties, such as the use of conducting polymers [13], plasma treatment [14,15], deposition of metallic [16] and oxide [10,17] nanoparticles. Plasma functionalization makes it possible to significantly improve capturing of ammonia molecules on the surface of carbon nanotubes. In [18] the oxygen plasma was used for modification of multi-walled carbon nanotubes, the sensitivity of modified gas sensors towards ammonia was twice higher than that of untreated sensing material. Treatment of MWCNTs in oxygen plasma and plasma copolymerization of maleic anhydride (MA) and acetylene [19] led to the formation of core-shell structures with relatively high response (22.5\% towards $100 \mathrm{ppm} \mathrm{NH})$. Kim et al. [15] created ammonia gas sensor based on $\mathrm{O}_{2}$ functionalized MWCNT/PANI sensor reaching the response $3.34 \% /\left(\mathrm{ppm} \mathrm{NH}_{3}\right)$ within a range $10-100 \mathrm{ppm} \mathrm{NH}_{3}$. 
In this paper, the effect of duration of plasma functionalization of MWCNTs using copolymerization of maleic anhydride and acetylene for ammonia gas sensor was investigated. This approach makes it possible to enhance the sensor response of MWCNTs to $\mathrm{NH}_{3}$ by means of increase of concentration of surface functional groups.

\section{Methods}

MWCNTs were deposited on $\mathrm{Si} / \mathrm{SiO}_{2}$ substrate by plasma enhanced chemical vapour deposition (PECVD). The growth of CNTs was carried out on iron catalytic nanoparticles. The nanoparticles were deposited in microwave plasma torch with dual-flow nozzle electrode according to the technique described in $[20,21]$. $\mathrm{Si} / \mathrm{SiO}_{2}$ substrate was placed in a holder for 4 samples with $4 \times 4 \mathrm{~mm}$ deposition area for each sample. The argon was used as a carrier gas. The flow rates of argon through the central and outer channels were 700 and $28 \mathrm{sccm}$, respectively. The outer channel was used to fed the $\mathrm{Fe}(\mathrm{CO})_{5}$ vapours. This compound forms $\mathrm{Fe}$ nanoparticles as a result of decomposition. The deposition of nanoparticles was carried out for $15 \mathrm{~s}$ with plasma power of $210 \mathrm{~W}$. The iron nanoparticles on the $\mathrm{Si} / \mathrm{SiO}_{2}$ substrate were placed into tubular furnace where the decomposition of acetylene was performed at $600{ }^{\circ} \mathrm{C}$. Firstly, the samples were reduced in $\mathrm{Ar}(1400 \mathrm{sccm}) / \mathrm{H}_{2}(500 \mathrm{sccm})$ mixture for $10 \mathrm{~min}$, then the flow was switched to $\mathrm{Ar}(1400 \mathrm{sccm}) / \mathrm{C}_{2} \mathrm{H}_{2}(25 \mathrm{sccm})$ and the deposition of CNTs was carried out for $10 \mathrm{~min}$. Subsequently, the active layer of sensors was covered by gold contacts ( $325 \mathrm{~nm}$ layer, $6.65 \mathrm{~mm} \times 2.33 \mathrm{~mm}$ ) with $25-\mathrm{nm}$ thick $\mathrm{NiCr}$ interlayer.

MWCNT sensors was plasma treated in $\mathrm{MA}-\mathrm{C}_{2} \mathrm{H}_{2}$ plasma using the equipment described in [21,22]. Briefly, the sensor with sealed Au contacts was placed into special holder.The deposition of plasma polymer was carried out by dielectric barrier discharge (DBD) plasma co-polymerization of $\mathrm{MA}$ and $\mathrm{C}_{2} \mathrm{H}_{2}$. The discharge was ignited between planar metallic electrodes covered by $\mathrm{Al}_{2} \mathrm{O}_{3}$ ceramics, 1-mm thick, on the bottom of which the sensor was placed. The gases were supplied by a 1 $\mathrm{mm}$ slit between the high voltage electrodes. The vapors of MA were fed into the discharge by means of Ar flow (Messer, 99.998\%) purging throw the MA pellets (Sigma-Aldrich, 99\%). The flow rate of the second monomer, $\mathrm{C}_{2} \mathrm{H}_{2}$ (Messer, 99.6\%) was set to $2 \mathrm{sccm}$. The Ar flow rate through the bubbler was $0.5 \mathrm{slm}$. The total Ar flow rate was kept at the level of $1.5 \mathrm{slm}$. The deposition was carried out in the discharge ignited by $5.4 \mathrm{kHz}$ sinusoidal high voltage. The power supplied by the generator was $20 \mathrm{~W}$. Three samples of gas sensors with various durations of deposition ( $2 \mathrm{~min}, 5 \mathrm{~min}$, and $7 \mathrm{~min}$ ) were obtained.

The gas sensor was characterized by means of measuring the resistance of sensor under ammonia exposure. The measurements were performed using a custom made setup with two gas channels: synthetic air (Linde) and the analyte $\left(\mathrm{NH}_{3}\right.$ diluted in air). The scheme of the setup was described in [23] in detail. The sensor was placed into the measuring chamber on the heater, operated by an Agilent U3606A DC power supply (Agilent). The resistance of active layer of sensor was measured by the two point technique between the gold electrodes using Keithley 2410 Source Meter (Keithley). A fixed bias voltage $1 \mathrm{~V}$ was applied. The sensor response was calculated as

$$
\frac{\Delta R}{R_{0}}=\frac{R-R_{0}}{R_{0}}
$$

where $R$ and $R_{0}$ are the resistances of sensors in a mixture synthetic air/ $\mathrm{NH}_{3}$ and in a pure synthetic air, respectively. The concentration of ammonia was varied from $100 \mathrm{ppm}$ to $500 \mathrm{ppm}$. All samples were tested at the same conditions, room temperature $\left(25 \pm 2{ }^{\circ} \mathrm{C}\right)$ and relative humidity $2-2.5 \%$.

Current-voltage (I-V) characteristics of the sensors were measured by $4200-S C S$ Semiconductor characterization system (Keithley) within a range from $-5 \mathrm{~V}$ to $+5 \mathrm{~V}$ at room temperature $\left(25^{\circ} \mathrm{C}\right)$. Morphology of the CNT sensing material was determined by scanning electron microscopy (SEM) using Tescan MIRA (TESCAN) equipped with electron-dispersive X-ray spectroscopy add-on. Disorder degree of CNTs was determined by Raman spectroscopy using Renishaw spectrometer (Renishaw) in a range of $-100-3200 \mathrm{~cm}^{-1}(\lambda=514 \mathrm{~nm})$. X-ray photoelectron spectroscopy (XPS) was used to analyze the chemical composition of surface layers using EA125 spectrometer fitted on 
custom built UHV system. The measurements were used at pass energy of $25 \mathrm{eV}$ and power $270 \mathrm{~W}$. To excite XPS spectra $\mathrm{Al} \mathrm{K} \alpha$ radiation $(1486.6 \mathrm{eV})$ was used.

\section{Results and Discussion}

SEM images of the functionalized MWCNTs used as active material of ammonia gas sensor are presented in Figure 1. As it can be seen, the morphology of carbon nanotubes remains almost unchanged after plasma functionalization with maleic anhydride because of low duration of treatment and relatively mild conditions. The samples of MWCNTs deposited directly on $\mathrm{Si} / \mathrm{SiO}_{2}$ substrate were represented by strongly entangled carbon nanotubes with large number of walls. The sample also contained small fraction of cup-stacked carbon nanofibers.

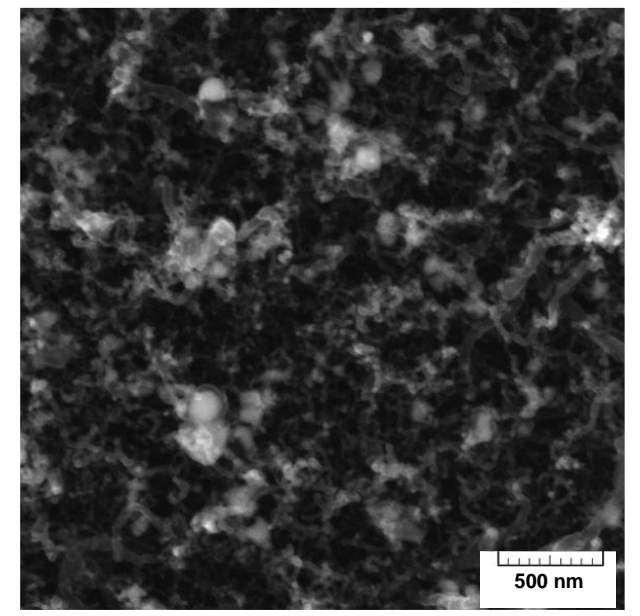

(a)

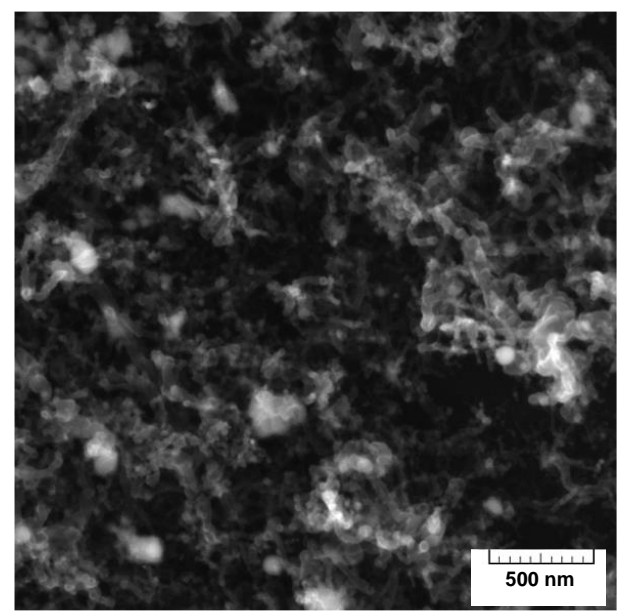

(b)

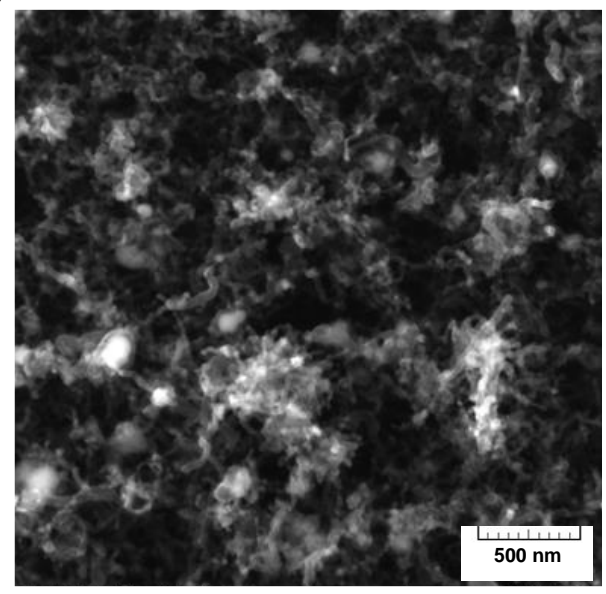

(c)

Figure 1. SEM images of MWCNTs before and after functionalization at various durations: (a) 2 min, (b) $5 \mathrm{~min},(\mathbf{c}) 7 \mathrm{~min}$

Raman spectra of plasma treated MWCNTs are shown in Figure 2a. The spectra of plasma functionalized MWCNTs consist of two bands typical for carbon nanomaterials, D mode $\left(1353 \mathrm{~cm}^{-1}\right)$ which can be attributed to disorder structure and G mode (1589-1592 $\left.\mathrm{cm}^{-1}\right)$ relating to graphitic structure of the material [24,25]. The ratio of intensity of these two modes indicates the disorder degree of the material. Plasma treatment leads to the increase of $I(D) / I(G)$ (Table 1) indicating the decrease of contribution of C-C bonds in the form of $\mathrm{sp}^{2}$ hybridization. It can be noted that any treatment of MWCNTs can produce a lot of defects on its surface, but the results on I(D)/I(G) confirm relatively mild conditions of plasma functionalization compared to other types of treatment, such as chemical functionalization reported in [26]. 


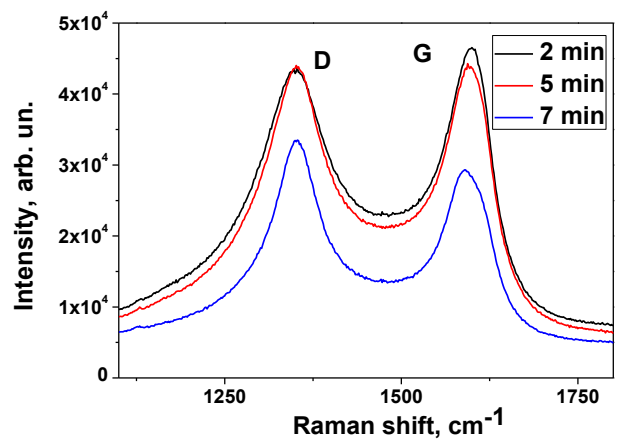

(a)

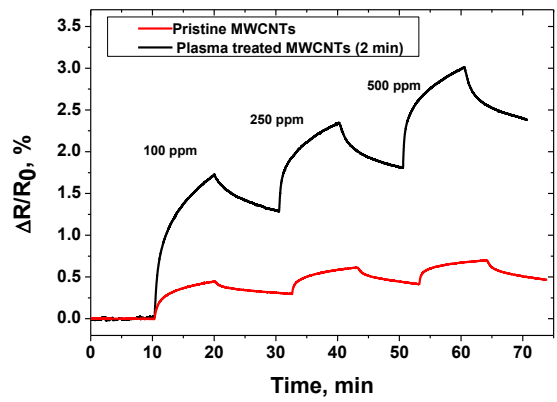

(c)

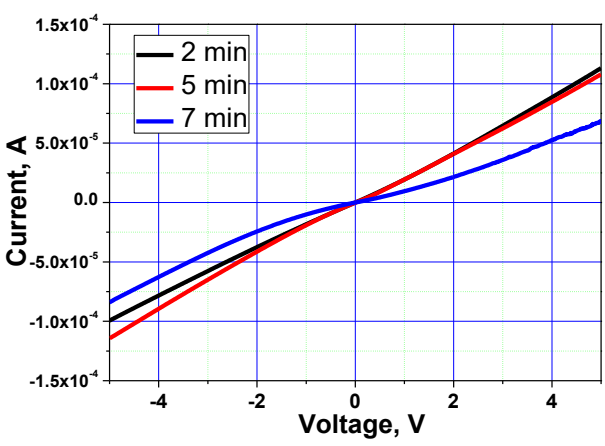

(b)

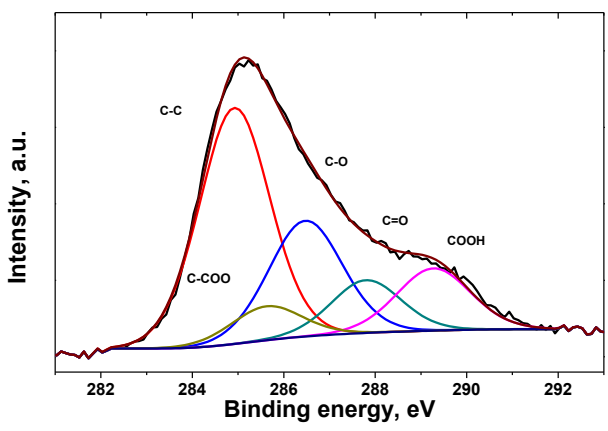

(d)

Figure 2. (a) Raman spectra of samples obtained using various durations of plasma treatment; (b) I-V curves of active layer of gas sensor; (c) Typical response curve of pristine MWCNTs and MWCNTs plasma treated for $2 \mathrm{~min}$; (d) XPS spectrum of MWCNT sample plasma treated for $2 \mathrm{~min}$.

Table 1. Parameters of Raman spectra of plasma treated MWCNTs.

\begin{tabular}{cccccc}
\hline Sample & $\begin{array}{c}\text { D Peak Position, } \\
\mathbf{c m}^{-\mathbf{1}}\end{array}$ & $\begin{array}{c}\text { D Peak FWHM, } \\
\mathbf{c m}^{-\mathbf{1}}\end{array}$ & $\begin{array}{c}\text { G Peak Position, } \\
\mathbf{c m}^{-\mathbf{1}}\end{array}$ & $\begin{array}{c}\text { G Peak FWHM, } \\
\mathbf{c m}^{-\mathbf{1}}\end{array}$ & I(D)/I(G) \\
\hline 2 min & 1353 & 130 & 1591 & 65 & 0.87 \\
$5 \mathrm{~min}$ & 1353 & 119 & 1592 & 70 & 0.95 \\
$7 \mathrm{~min}$ & 1353 & 90 & 1589 & 59 & 1.08 \\
\hline
\end{tabular}

I-V curves of the active layer of ammonia gas sensors are presented in Figure $2 \mathrm{~b}$. Current-voltage (I-V) characteristic of sensor treated during 2 min was almost linear that corresponds to conductive material. Increasing of the treatment time led to appearance of non-linearity of the I-V curve due to change of conduction mechanism to semiconducting because of functional coating formed on the carbon surface.

Sensor responses are shown in Table 2.

Table 2. Response of gas sensors before and after functionalization of MWCNT active layer.

\begin{tabular}{|c|c|c|c|c|c|c|c|}
\hline \multirow{2}{*}{$\begin{array}{l}\text { Duration of } \\
\text { Treatment }\end{array}$} & \multirow[t]{2}{*}{$\begin{array}{c}\text { Resistance of } \\
\text { Sensor, } \mathbf{k} \Omega\end{array}$} & \multicolumn{3}{|c|}{$\begin{array}{c}\text { Sensor Response } \\
\text { before Functionalization, } \\
\%\end{array}$} & \multicolumn{3}{|c|}{$\begin{array}{c}\text { Sensor Response } \\
\text { after Functionalization, } \\
\%\end{array}$} \\
\hline & & $\begin{array}{c}100 \\
\mathrm{ppm}\end{array}$ & $\begin{array}{c}250 \\
\mathrm{ppm}\end{array}$ & $\begin{array}{c}500 \\
\text { ppm }\end{array}$ & $\begin{array}{c}100 \\
\text { ppm }\end{array}$ & $\begin{array}{c}250 \\
\mathrm{ppm}\end{array}$ & $\begin{array}{c}500 \\
\mathrm{ppm}\end{array}$ \\
\hline $2 \min$ & 52.7 & & & & 1.7 & 2.3 & 2.9 \\
\hline $5 \mathrm{~min}$ & 58.6 & 0.4 & 0.6 & 0.7 & 1.8 & 2.6 & 3.6 \\
\hline $7 \mathrm{~min}$ & 110 & & & & 0.7 & 1.0 & 1.3 \\
\hline
\end{tabular}

The resistance of sensors grows when increasing the duration of treatment due to the formation of plasma coating on the surface of MWCNTs. The resistance of initial non-treated MWCNTs was 
only $18 \mathrm{k} \Omega$, and the plasma treatment led to the increase of resistance to $52.7-110 \mathrm{k} \Omega$. This fact is caused by the formation of relatively thin film of plasma polymer on the surface of MWCNTs.

Typical curves of sensor response are shown in Figure 2c. The response of gas sensors was within a range $0.3-0.6 \%$ for $100-500 \mathrm{ppm} \mathrm{NH}$. Plasma treatment led to the growth of sensor response to $1.7-$ $2.9 \%$ ( $2 \mathrm{~min}$ ). The maximum response was observed at $5 \mathrm{~min}$ of treatment and further growth of duration of treatment led to the decrease of response to $0.7-1.3 \%(100-500 \mathrm{ppm})$. This is in agreement with O/C determined by XPS which was $0.28,0.35$, and 0.335 for $2 \mathrm{~min}, 5 \mathrm{~min}$, and $7 \mathrm{~min}$, respectively. Typical XPS spectrum of the sample treated for $2 \mathrm{~min}$ is presented in Figure $2 \mathrm{~d}$. The data show that the increase of duration of treatment above some level $(5 \mathrm{~min})$ led to the formation of lower concentration of surface oxygen-containing functional groups.

\section{Conclusions}

The presented results show that plasma functionalization of MWCNTs can be effective in the enhancement of ammonia detection using the room temperature gas sensors. Plasma functionalization made it possible to increase the sensor response towards ammonia by 3-4 times compared to pristine MWCNTs. The increase of duration of plasma functionalization induces the rise of $\mathrm{O}: \mathrm{C}$ from 0.28 to 0.335 , the increase of sensor resistance, and the distortion of shape of I-V curves.

Author Contributions: Methodology, Writing-Original Draft Preparation, A.G.B.; Resources, Measurements, A.M. All authors participated in the discussions of the results.

Funding: The work was funded by the State task of Ministry of Science and Higher Education of Russia (project no. FSUN-2020-0008).

Conflicts of Interest: The authors declare no conflict of interest.

\section{References}

1. Arjmand, M.; Mahmoodi, M.; Gelves, G.A.; Park, S.; Sundararaj, U. Electrical and electromagnetic interference shielding properties of flow-induced oriented carbon nanotubes in polycarbonate. Carbon $\mathrm{N}$. Y. 2011, 49, 3430-3440.

2. Bannov, A.G.; Nazarenko, O.B.; Maksimovskii, E.A.; Popov, M.V.; Berdyugina, I. Thermal behavior and flammability of epoxy composites based on multi-walled carbon nanotubes and expanded graphite: A comparative study. Appl. Sci. 2020, 10, 6928.

3. Guo, J.; Wang, J.; Xuan, C.; Wu, Z.; Lei, W.; Zhu, J.; Xiao, W.; Wang, D. Molybdenum carbides embedded on carbon nanotubes for efficient hydrogen evolution reaction. J. Electroanal. Chem. 2017, 801, 7-13.

4. Nguyen, T.K.; Bannov, A.G.; Popov, M.V.; Yun, J.-W.; Nguyen, A.D.; Kim, Y.S. High-temperature-treated multiwall carbon nanotubes for hydrogen evolution reaction. Int. J. Hydrogen Energy 2018, 43, 6526-6531.

5. Pekarek, J.; Vrba, R.; Prasek, J.; Jasek, O.; Majzlikova, P.; Pekarkova, J.; Zajickova, L. MEMS Carbon Nanotubes Field Emission Pressure Sensor With Simplified Design: Performance and Field Emission Properties Study. IEEE Sens. J. 2015, 15, 1430-1436.

6. Wang, J. Carbon-nanotube based electrochemical biosensors: A review. Electroanalysis 2005, 17, 7-14.

7. Fam, D.W.; Tok, A.I.; Palaniappan, A.; Nopphawan, P.; Lohani, A.; Mhaisalkar, S.G. Selective sensing of hydrogen sulphide using silver nanoparticle decorated carbon nanotubes. Sensors Actuators B Chem. 2009, 138, 189-192.

8. Mittal, M.; Kumar, A. Carbon nanotube (CNT) gas sensors for emissions from fossil fuel burning. Sensors Actuators B Chem. 2014, 203, 349-362.

9. Rigoni, F.; Tognolini, S.; Borghetti, P.; Drera, G.; Pagliara, S.; Goldoni, A.; Sangaletti, L. Enhancing the sensitivity of chemiresistor gas sensors based on pristine carbon nanotubes to detect low-ppb ammonia concentrations in the environment. Analyst 2013, 138, 7392-7399.

10. Kaushik, P.; Eliáš, M.; Michalička, J.; Hegemann, D.; Pytlíček, Z.; Nečas, D.; Zajíčková, L. Atomic layer deposition of titanium dioxide on multi-walled carbon nanotubes for ammonia gas sensing. Surf. Coat. Technol. 2019, 370, 235-243.

11. Kumar, S.; Pavelyev, V.; Mishra, P.; Tripathi, N. A review on chemiresistive gas sensors based on carbon nanotubes: Device and technology transformation. Sensors Actuators A. Phys. 2018, 283, 174-186. 
12. Mendes, R.G.; Wr, P.S.; Bachmatiuk, A.; Sun, J.; Gemming, T.; Liu, Z.; Rümmeli, M.H. Carbon nanostructures as a multi-functional platform for sensing applications. Chemosensors 2018, 6, 60.

13. Si, P.; Mortensen, J.; Komolov, A.; Denborg, J.; Møller, P.J. Polymer coated quartz crystal microbalance sensors for detection of volatile organic compounds in gas mixtures. Anal. Chim. Acta 2007, 597, 223-230.

14. Ionescu, R.; Espinosa, E.H.; Sotter, E.; Llobet, E.; Vilanova, X.; Correig, X.; Felten, A.; Bittencourt, C.; Van Lier, G.; Charlier, J.C.; et al. Oxygen functionalisation of MWNT and their use as gas sensitive thick-film layers. Sensors Actuators B Chem. 2006, 113, 36-46.

15. Kim, T.; Kim, S.; Min, N.; Pak, J.J.; Lee, C.; Kim, S. NH3 sensitive chemiresistor sensors Using plasma functionalized multiwall carbon nanotubes/conducting polymer composites. IEEE SENSORS 2008 Conf. 2008, 208-211, doi:10.1109/ICSENS.2008.4716419.

16. Nguyen, L.Q.; Phan, P.Q.; Duong, H.N.; Nguyen, C.D.; Nguyen, L.H. Enhancement of NH3 gas sensitivity at room temperature by carbon nanotube-based sensor coated with Co nanoparticles. Sensors 2013, 13, $1754-1762$.

17. Rigoni, F.; Drera, G.; Pagliara, S.; Goldoni, A.; Sangaletti, L. High sensitivity, moisture selective, ammonia gas sensors based on single-walled carbon nanotubes functionalized with indium tin oxide nanoparticles. Carbon N. Y. 2014, 80, 356-363.

18. Ham, S.W.; Hong, H.P.; Kim, J.H.; Min, S.J.; Min, N.K. Effect of oxygen plasma treatment on carbon nanotube-based sensors. J. Nanosci. Nanotechnol. 2014, 14, 8476-8481.

19. Bannov, A.G.; Jašek, O.; Manakhov, A.; Márik, M.; Nečas, D.; Zajíčková, L. Investigation of pristine graphite oxide as room-temperature chemiresistive ammonia gas sensing material. Sensors 2017, 17, 1964-1970.

20. Synek, P.; Jašek, O.; Zajíčková, L. Study of microwave torch plasmachemical synthesis of iron oxide nanoparticles focused on theanalysis of phase composition. Plasma Chem. Plasma Process. 2014, 34, 327-341.

21. Bannov, A.G.; Jašek, O.; Manakhov, A.; Márik, M.; Nečas, D.; Zajíčková, L. High-performance ammonia gas sensors based on plasma treated carbon nanostructures. IEEE Sens. J. 2017, 17, 1964-1970.

22. Manakhov, A.; Michlíček, M.; Nečas, D.; Polčák, J.; Makhneva, E.; Eliáš, M.; Zajíčková, L. Carboxyl-rich coatings deposited by atmospheric plasma co-polymerization of maleic anhydride and acetylene. Surf. Coatings Technol. 2015, 295, 37-45.

23. Bannov, A.G.; Prášek, J.; Jašek, O.; Zajíčková, L. Investigation of pristine graphite oxide as roomtemperature chemiresistive ammonia gas sensing material. Sensors 2017, 17, 320.

24. Ferrari, A.; Robertson, J. Resonant Raman spectroscopy of disordered, amorphous, and diamondlike carbon. Phys. Rev. B 2001, 64, 075414.

25. Ferrari, A.C. Raman spectroscopy of graphene and graphite: Disorder, electron-phonon coupling, doping and nonadiabatic effects. Solid State Commun. 2007, 143, 47-57.

26. Avile, F. Evaluation of mild acid oxidation treatments for MWCNT functionalization. Carbon N. Y. 2009, 7, 5-10.

C 2020 by the authors. Submitted for possible open access publication under the terms and conditions of the Creative Commons Attribution (CC BY) license (http://creativecommons.org/licenses/by/4.0/). 